\title{
Use of Insecticide treated bed nets amongst Public Health Physicians in Nigeria
}

\author{
Nwokeukwu H.I ${ }^{1}$, Emma- Ukaeghu U. C ${ }^{1}$, Inya-Agha D ${ }^{1}$, Iwuoha E.C ${ }^{2}$ \\ 1.Department of community Medicine Federal Medical Centre, Umuahia, Abia State, Nigeria \\ 2. Department of community medicine, Abia State University Teaching Hospital Aba, Abia state, Nigeria
}

\begin{abstract}
BACKGROUND: Malaria contributes to high morbidity and mortality rate in both young and old in this part of the world. One of the methods for the prevention of malaria is the use of Insecticide treated bed nets. These were distributed to household. It is therefore very important to know, if the people who are advocating the use like the public health physicians are actually practicing it. OBJECTIVE: To determine the access of insecticide treated bed nets (ITNs) to the public health physicians and to determine the utilization of the ITNs. METHODS: A cross sectional study was carried out with structured questionnaire distributed to all consented public health physicians who were around when the questionnaire were distributed at the Association conference held during the election year 2013 in Ilorin, Nigeria. RESULTS: Out of the two hundred questionnaire distributed 174 (87\%) were collected back. There were females $88(51 \%)$ and males $86(49 \%)$. The majority 79 (48\%) of the respondent who indicated their ages were age group of 31-40 years. About 110(63.2\%) had access to ITNs while 37(33.6) out of them always use it and most non-utilization factor was sweating. CONCLUSION: Although a good number of the respondent have access to the nets only few use it due to the tropical nature of resource limited country like Nigeria. It is therefore necessary to manufacture user-friendly ITNs.
\end{abstract}

Key words: Insecticide Treated Nets, Physicians

\section{Introduction}

Malaria is endemic in this part of the world and it is responsible for $60 \%$ outpatient visits to health facilities, $30 \%$ childhood death, $25 \%$ of death in children under one year, $11 \%$ maternal death. The financial loss due to malaria annually is estimated to be about 132 billion Naira in form of treatment costs, prevention, loss of man-hours etc, yet, it is a preventable and treatable disease ${ }^{1}$

Insecticide-treated nets (ITNs) are a key prevention tool that have been found to reduce uncomplicated malaria in children by $51 \%$ and decrease all-cause mortality by $18 \%$ in children aged $1-59$ months $^{2}$.By preventing malaria, LLINs reduce the need for treatment and the pressure on health services ${ }^{3}$.

Previous malaria prevention strategies aimed for high levels of ownership and use of insecticide-treated nets (ITNs) by vulnerable groups for example, pregnant women, children below 5 years. More recently, the goal has shifted to 'Universal Coverage', whereby every person living in a malarious area sleeps under an ITN, preferably a Long-lasting Insecticidal Net (LLIN) ${ }^{4}$.

With the significant increase in funding in the recent decade, many countries across sub-Saharan Africa, including Nigeria, are rapidly increasing ITN ownership, through several strategies including, social marketing ${ }^{5,6.7}$, free distribution to target groups (through antenatal care (ANC) or immunization campaigns ${ }^{8-12}$, and more recently, free universal population-based distribution campaigns targeting the entire population at risk $^{6,8,12,13,14}$.

In order to improve access to LLINs, the Federal government under the National Malaria Control Programme embarked on free mass distribution of LLINs in public primary health facilities, with the aim of ensuring wide-scale, rapid and equitable deployment of LLINs. The LLINs were distributed through routine distribution methods and campaigns.

It is therefore very important to know, if the people who are advocating the use like the Public health physicians are actually practicing it.

Objectives

- To determine the access of insecticide treated bed nets (ITNs) to the public health physicians

- To determine the utilization of the ITNs

\section{Methodology}

A cross sectional study was carried out with structured questionnaire distributed to all consenting Public Health Physicians who were around when the questionnaires were distributed at the Association Conference held during the election year 2013 in Ilorin, Kwara State, Nigeria. 
Long lasting Insecticidal Nets(LLIN): A factory-treated mosquito net with insecticide incorporated into or bound around the fibres, or a mosquito net treated with a long-lasting insecticidal treatment kit, that retains its biological activity for at least 20 WHO standard washes under laboratory conditions and 3 years of recommended use under field conditions without re-treatment ${ }^{4}$.

Access: A person is said to have access to an LLIN if there is an LLIN available for that person to sleep under every night. Whether or not the person does sleep under the LLIN is an issue of use, not an issue of access ${ }^{4}$. The sample size calculated was 136. However 200 questionnaires were distributed. The data collected was analyzed with Excel and Epi-info

\section{Results}

Out of the two hundred questionnaires distributed $174(87 \%)$ were collected back and 26(13\%) did not respond. There were Females 88(51\%) and Males 86(49\%). The majority79 (48\%) were age group of 34-43 years. About $110(63.2 \%)$ had access to ITNs while $37(33.6 \%)$ out of them always use it and most common factor responsible for non-utilization was sweating 33(30.3\%), not necessary 13(11.9\%), net in the window 11 $(10.1 \%)$, Forgot $11(10.1 \%)$, irritable $7(6.4 \%)$. Other methods used by the respondents in prevention of malaria were mostly clean environment $136(20.3 \%)$, followed by indoor sprays $128(18.5 \%)$ and then clearing vegetations100 (15\%). Most of them got the nets through Universal ITNs Campaign 54(37\%), Market 38(26\%), Friends 19(13\%) and Antenatal 13(9\%).

Table I Demographic Data

\begin{tabular}{|c|c|c|}
\hline Sex & Frequency & Percentage \\
\hline Male & 86 & 49.5 \\
\hline Female & 88 & 50.5 \\
\hline \multicolumn{3}{|l|}{ Age Group } \\
\hline 21-30 & 18 & 10.7 \\
\hline $31-40$ & 86 & 51.2 \\
\hline $41-50$ & 41 & 24.4 \\
\hline $51-60$ & 16 & 9.5 \\
\hline$>60$ & 7 & 4.2 \\
\hline \multicolumn{3}{|l|}{ Designation } \\
\hline Consultants & 63 & 37.5 \\
\hline Medical Officer & 12 & 7.1 \\
\hline Senior Registrar & 27 & 16.1 \\
\hline Registrar & 64 & 38.1 \\
\hline \multicolumn{3}{|l|}{ Marital Status } \\
\hline Married & 144 & 84.2 \\
\hline Single & 24 & 14.4 \\
\hline Widow & 2 & 1.2 \\
\hline Divorced & 1 & 0.6 \\
\hline
\end{tabular}

\section{Figure 1: Access and Use of ITNs by} Public Health Physicians

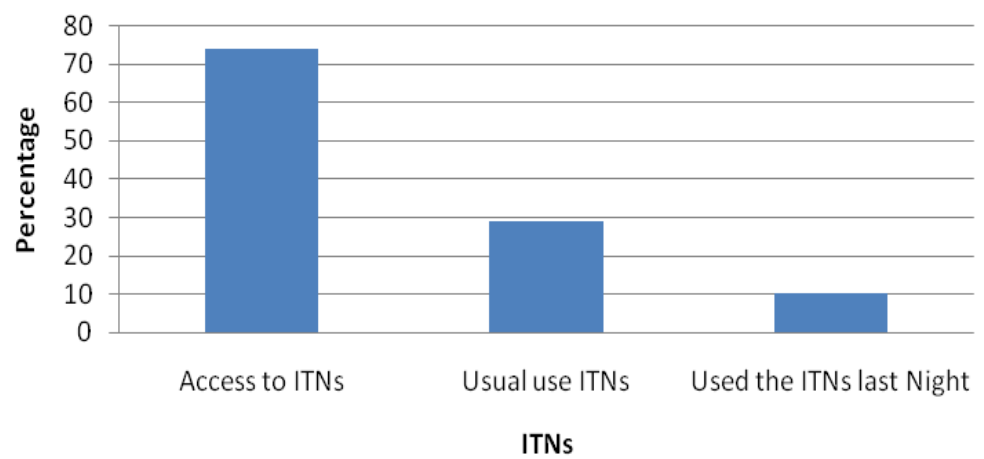

Majority 128(73.6) had access to Insecticide treated bed Nets(ITNs) but only 37(29\%) usually use the ITNs and $13(10 \%)$ used it last night. $\mathrm{P}$ value $<.05$ is staistically significant. 


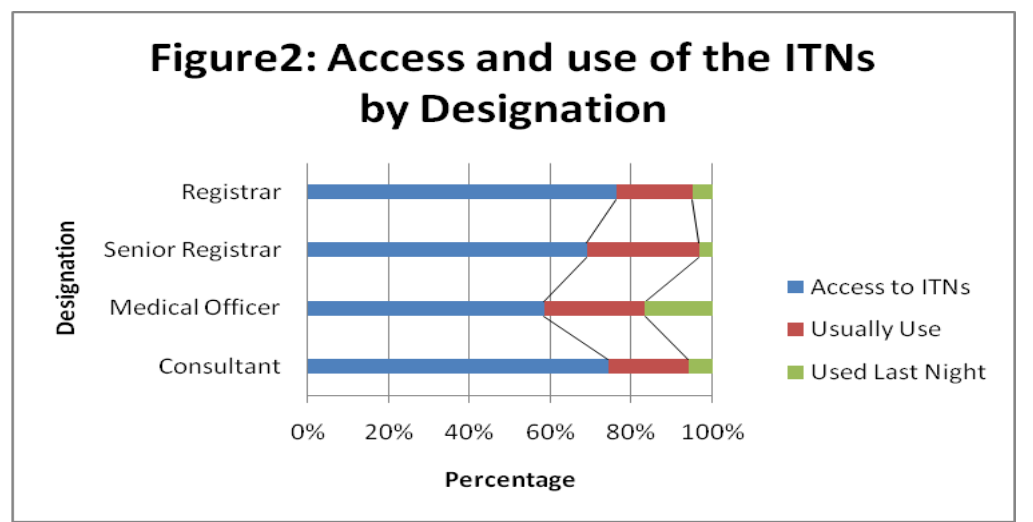

The Consultants had the highest access to ITNs 49(77.8\%), followed by Registrar45(70.3\%). However the Medical Officer 3(42.8\%) and senior Registrar $8(40 \%)$ had higher percentage of those that had access usually use the net while mainly medical officers $2(28.6 \%)$ used the nets lat night.

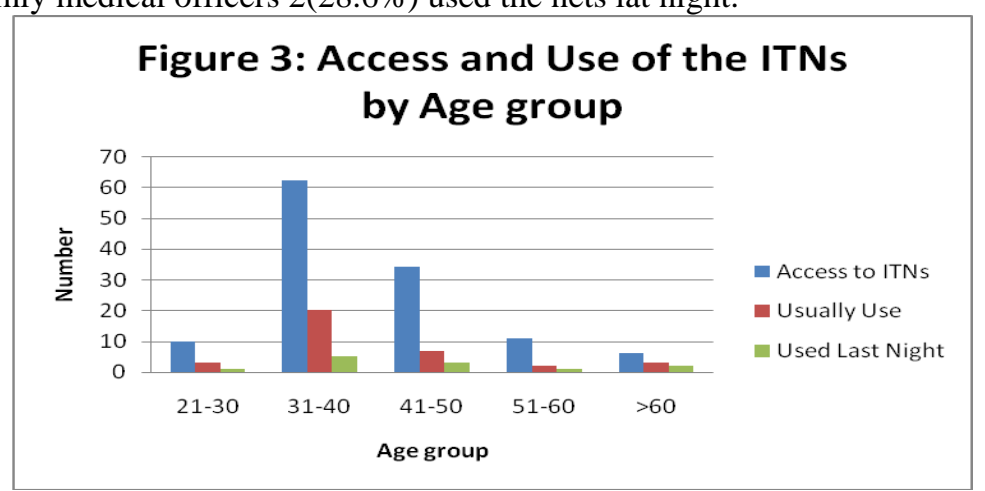

The age group 31-40 had the highest access to ITNs also most usually use the nets and used last night followed by age group 41-50 years

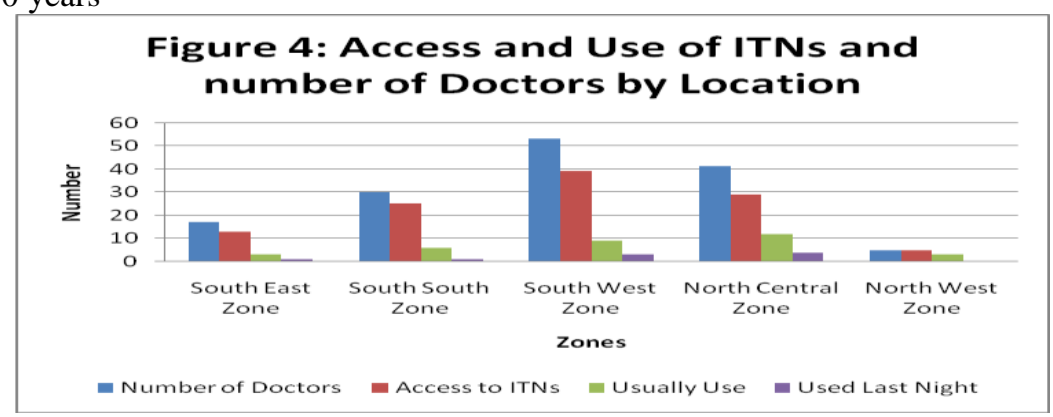

The respondent and access to the nets were more from the South West Zone while the North Central Usually and used it last night most.

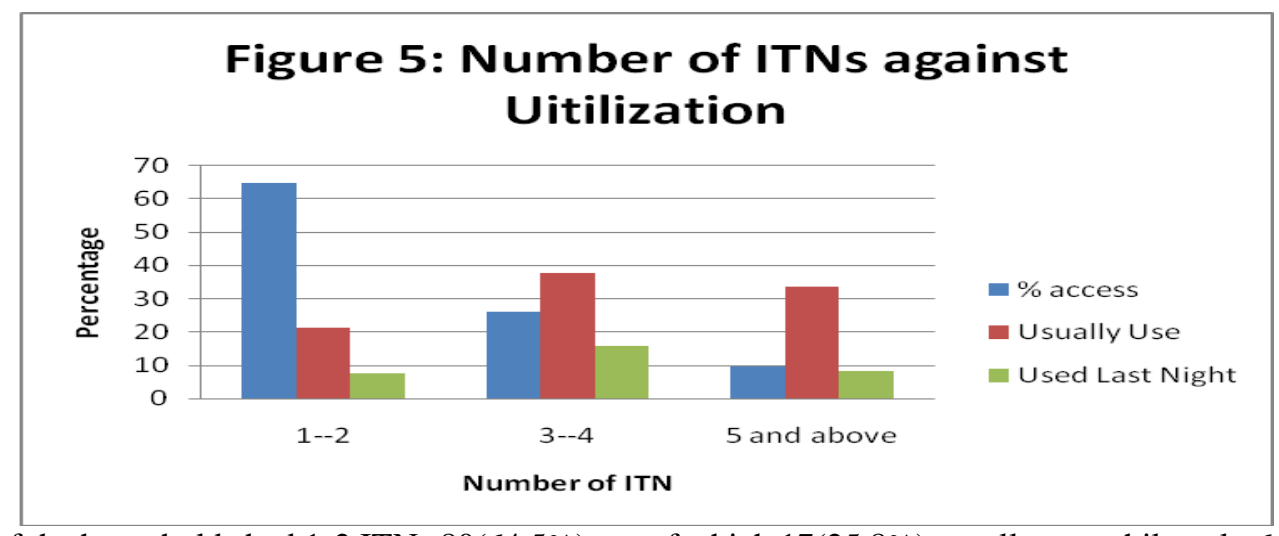

Majority of the households had 1-2 ITNs $80(64.5 \%)$ out of which $17(25.8 \%)$ usually use while only $6(9.5 \%)$ used it last night. The number of Housholds with 3-4 nets were 32(21.2\%) but most of them used the net. Out of these $13(37.5 \%$ ) usually use it and $33.3 \%$ used it last night. The same with 5 and above except it is slighly lower than 3-4 nets in housholds. $\mathrm{P}$ value is $<0.05$, it is statistically significant. 


\section{Discussion}

The good number of the Community Health Physicians responded, this showed that many people are conversant with insectide treatment Nets. The physicians were more of females this could be another reason for good response since women and children were the vulneranble group targeted initially before the universal distribution of the nets. This may actually show that females are well represented or dominated Community Health Department.

The access to the insecticide treated bed nets was very high. This is in constrast to the findings of the Nigerian national demographic and Health survey of $2008^{15}$ and the Malawi demographic survey in 2000 and $2004^{16}$ although there was increase in Malawi in 2004 but it was only to 35\%. The result from this study is similar to the findings in Kenya ${ }^{17}$ among children less than 5 years and also the study done in kano state, Northern Nigeria showed increase from $10 \%$ to $70 \% .{ }^{18}$ Another suvey done in Anambra State, Eastern Nigeria showed a very high coverage of $80.5 \%$ with LLINs. ${ }^{19}$

Athough the access was high the utilization was low. Those who usaually sleep under the net was higher than those who slept under the net last night, this could be due to the fact that most people did not sleep in their houses since they came for conference propably slept in the hotel without ITNs. The number that usually sleep under the net was still not encouraging. The result in this study is in constrast with high percentage of people who slept under the net last night in study done in $\mathrm{Kano}^{18}$ and Anambra ${ }^{19}$ States Nigeria. However in both studies those who slept under the net last night were still lower than those had the night. The study has shown that many people who has the nets do not actually sleep under it. The reason given by most respondents was sweating, this could be the tropical nature of the climate.

Although the number that had possession of the nets were mainly consultants and registrars but the most usually used and used last night were the medical officers and senior registrar this could be due to the medical officers may be from the ministry and were at home to use it.

Those with the nets, usually use and used last night were most in age group 31-40 this could be due to being the active age group with children and women of child bearing group among the venurable group that the nets were distributed earlier, before the universal distribution. The household could have received more nets during the distribution of venurable group and universal period.

Although the number of physicians, access to ITNs and usually use where more from South Western Nigeria, most of the people who used the ITNs last night were mainly from the North central Nigeria this could be because Ilorin where the conference was taking place was in North central and most of them could have slept in their houses last Night unlike those travelled from other Zones and slept in the Hotels.

Although most of the people had 1-2 ITNs similar to the study in Anambra state Nigeria ${ }^{19}$, but majority of those who had more than 2 nets slept under the net. This could be due to the fact that the children and pregnant mothers will be considered first. Therefore if more are left the adults will have the chances of using the remaining nets. Although most of the respondents got their nets through the universl ITNs Campaign, good number bought from the market it is difficut to explain why people will not even use what they spent their money to purchase. Other methods mainly used to prevent malaria were clean environment, aerosol spray and clearing vegetations.

\section{Conclusion}

Although a good number of the respondent had access to the nets only few used it due to the tropical nature of resource limited country like Nigeria. It is therefore necessary to manufacture user-friendly ITNs. It is a thing of note that the preacher of ITN's the Public Health Doctors was not using it, so it will difficult to get the community to use it. It is therefore important to intensify health education and supply enough net per household to be able to effect behavioural change concerning the use of available ITNs.

Ethical Consideration: Ethical approval was gotten from the ethical committee of Federal Medical Centre, Umuahia: Assigned number: FMC/QEH/G.596/Vol.10/049

Competing Interest: The authors declare no competing interest.

Approval by the Authors: The authors approved the publication of the manuscript.

\section{References}

[1]. Federal Ministry of Health, National Malaria Control Programme, 2011. Available at http://www.nmcpnigeria.org.

[2]. Eisele TP, Larsen D, Steketee RW: Protective efficacy of interventions for preventing malaria mortality in children in Plasmodium falciparum endemic areas. Int J Epidemiol 2010, 39(1):i88-i101. doi:Available at http://ije.oxfordjournals.org/content/39/suppl_1/i88.long. 2.

[3]. Obinna Onwujekwe, Benjamin Uzochukwu, Nkoli Ezumah, Elvis Shu: Increasing coverage of insecticide treated nets in rural Nigeria: implication of consumer knowledge, preferences and expenditures for malaria prevention. Malaria journal 2005, 4:29.

[4]. RBM Vector Control Working Group. Continuous Long-lasting Insecticidal Net Distributions: A Guide to Concepts and Planning. 2011, pp 4-5.

[5]. Noor A et al: Insecticide-treated net coverage in Africa: mapping progress in 2000-07. Lancet 2009, 373:58-67. 
[6]. Noor AM et al. Increasing coverage and decreasing inequity in insecticide-treated bed net use among rural Kenyan children. PLoS Med 2007, 4:e255.

[7]. Grabowsky M: et al Sustained high coverage of insecticide-treated bednets through combined Catch-up and Keep-up strategies. Trop Med Int Health 2007, 12:815-822.

[8]. Beer $\mathbf{N}$ et al. System effectiveness of a targeted free mass distribution of long lasting insecticidal nets in Zanzibar. Tanzania Malar J 2010, 9:173.

[9]. Blackburn BG et al.Successful integration of insecticide-treated bed net distribution with mass drug administration in Central Nigeria. AmJTropMed Hyg 2006, 75:650-655.

[10]. Gerstl S et al. Long-lasting insecticide-treated net usage in eastern Sierra Leone-the success of free distribution. Trop Med Int Health 2010, 15:480-488.

[11]. Grabowsky $\mathrm{M}$ et al. Integrating insecticide-treated bednets into a measles vaccination campaign achieves high, rapid and equitable coverage with direct and voucher-based methods. Trop Med Int Health 2010,10:1151-1160.

[12]. Wolkon A et al. Rapid scale-up of long-lasting insecticide-treated bed nets through integration into the national immunization program during child health week in Togo, 2004. AmJTrop Med Hyg 2010, 83:1014-1019.

[13]. Teklehaimanot A, Sachs JD, Curtis C: Malaria control needs mass distribution of insecticidal bednets. Lancet 2007, 369:2143-2146.

[14]. Federal Ministry of Health and National Malaria Control Programme: Nigeria Strategic plan 20092013.Abuja,Nigeria.Availableat[http://nmcpnigeria.org/f/STRATEGIC\%20PLAN\%2020092013.pdf?PHPSESSID=9af62a6bf2a27f1e47ba845abc0b0c35].

[15]. 15 National Population Commission (NPC) [Nigeria] and ICF Macro 2009. Nigeria Demographic and Health Survey 2008. NPC and ICF Macro; Abuja, 2009

[16]. Mathanga DP and Bowie C. Malaria control in Malawi: are the poor being served? International Journal for Equity in Health 2007, 6:22.

[17]. Eng JLV et al. Assessing bed net use and non-use after long-lasting insecticidal net distribution: a simple framework to guide programmatic strategies. Malar J. 2010; 9: 133.

[18]. Yazoume Ye et al. Can universal insecticide-treated net campaigns achieve equity in coverage and use? The case of northern Nigeria. Malaria Journal 2012, 11:32, 1-10.

[19]. Available at http://www.malariajournal.com/content/11/1/32

[20]. Chinyere O Mbachu, Obinna E Onwujekwe et al. Examining equity in access to long-lasting insecticide nets and artemisinin-based combination therapy in Anambra state, Nigeria. BMC Public Health 2012, 12:315. 